\title{
Factors related to the outcome of inpatient rehabilitation in patients with neoplastic epidural spinal cord compression
}

\author{
H G A Hacking MD ${ }^{1} \mathrm{H} \mathrm{H} \mathrm{J} \mathrm{Van} \mathrm{As} \mathrm{MD}{ }^{2}$ G J Lankhorst $\mathrm{MD}^{3}$ \\ ${ }^{1}$ Physician, ${ }^{2}$ Specialist, Rehabilitation and Physical Medicine, Rehabilitation Centre \\ Amsterdam, Overtoom 283, 1054 HW Amsterdam; ${ }^{3}$ Professor of Rehabilitation and \\ Physical Medicine, Free University Hospital, de Boelelaan 1117, 1081 HV Amsterdam, \\ The Netherlands.
}

\begin{abstract}
In this study we have tried to develop a method to predict the survival and the functional outcome following neoplastic spinal cord injury (SCI), which can be helpful when selecting patients for an intensive inpatient rehabilitation programme. We reviewed the clinical records of all patients with neoplastic epidural spinal cord compression, admitted to any Dutch spinal cord unit (SCU) between $1-1-1985$ and $1-1-1990(n=74)$. According to the outcome on $1-1-1991$ the average stay at the SCU was 111 days, whereas the average survival after discharge was 423 days. Seven patients died during their stay. Of all of the factors analysed, six showed a positive relationship with prolonged survival (> one year after discharge) and improved functional level: tumour biology (lymphoma, myeloma, breast and kidney tumours); SCI as the presenting symptom of the malignancy; slow ( $>1$ week) progression rate of neurological symptoms; tumours treated with a combination of surgery and radiotherapy; (partial) bowel control at admission; and (partial) independence regarding transfer activities at admission. A sum score (range 0-6) of these indicators is introduced. A patient with a sum score of $0-1$ has zero probability of living longer than one year after discharge and 0.19 of functional improvement during stay at the SCU. A score of 5-6 yields probabilities of 0.77 and 0.92 respectively. We conclude that the sum score can be helpful when selecting patients for an intensive inpatient rehabilitation programme or modifying such a programme. Validation for application in a general hospital is needed.
\end{abstract}

Keywords: epidural neoplasms; metastasis; spinal cord compression; rehabilitation; prognosis.

\section{Introduction}

The frequency of metastatic tumours compressing the spinal cord is unknown, but one autopsy study estimated that approximately $5 \%$ of patients dying of cancer have spinal cord compression. ${ }^{1}$ Metastatic tumours of the spinal cord are three to four times more frequent than primary malignant tumours. ${ }^{2}$ Life expectancy of these patients is limited. The mean survival after neurological signs have developed is between 3 and 9 months. ${ }^{3-8}$ After one year only $2-37 \%$ are still alive. ${ }^{9-11}$ Important indicators of prognosis of patients with spinal metastases are: tumour biology, neurological deficit, progression rate of symptoms, therapy used and general medical status of the patient. ${ }^{2-9.11-16}$

A small minority of cancer patients with spinal cord compression are admitted to a spinal cord unit (SCU) for rehabilitation. We traced only one study which discussed the outcome of rehabilitation in these patients. ${ }^{17}$ Regrettably empirical data concerning the selection process of those SCI cancer patients who benefit from clinical rehabilitation were not published. ${ }^{17}$

In the present study we try to identify factors which can be helpful when selecting patients for an intensive inpatient rehabilitation programme. Selection in many cases is based upon prognosis of survival and 
anticipated functional outcome following discharge from the SCU. We therefore investigated indicators related to survival and functional outcome of those patients who were admitted to a spinal cord unit.

\section{Material and methods}

All patients admitted between 1-1-1985 and 1-1-1990 to any Dutch spinal cord unit with a diagnosis of spinal cord compression due to epidural neoplasms were analysed. Clinical records were reviewed and personal data, tumour biology, date of diagnosis, date of spinal cord injury, length of stay at the SCU and date of death were recorded. The progression rate of neurological symptoms was divided into four groups: symptoms developing within 12 hours, $12-48$ hours, 2-7 days, or after more than one week. Therapy used for treatment of the spinal cord injury consisted of surgery (decompressive laminectomy), radiotherapy, surgery followed by radiotherapy, or other procedures. General medical status was assessed at the moment of occurrence of the spinal cord injury as: tumour process in remission just before the epidural metastasis became manifest, tumour process active with multiple metastases, or spinal cord injury as the presenting symptom of the malignancy. The neurological data (at admission and discharge) included: level of lesion, muscle strength (Medical Research Council (MRC) scale), sensory loss (normal, incomplete or complete loss) and autonomic disturbances (bowel and bladder control). The functional performance of dressing, transfer activities, toileting and bathing was evaluated using a three-point scale: $0=$ independent, $1=$ some assistance, $2=$ complete help. Mobility was classified as: walking (with or without aids) indoors or outdoors, confined to wheelchair, or bedridden.

\section{Data analysis}

Data collection was completed on 1-1-1991 and the available data were subsequently analysed. In order to find indicators related to life expectancy, we studied two groups of patients, divided according to their length of survival after discharge from the spinal cord unit (dividing line one year). The likelihood ratio and odds ratio of all variables (indicators) were determined. Although frequently used to describe the quality of diagnostic tests, the likelihood ratios are well suited to study indicators of prognosis. ${ }^{18}$ A likelihood ratio for surviving longer than one year of 2 for tumour biology ' $X$ ' $(\operatorname{LR}(X)=2)$ means that this type of tumour is found twice as often in patients who survive at least one year as in patients who die within one year. The likelihood ratio for all other types of tumour taken together could be $0.8(\mathrm{LR}($ non $\mathrm{X})=0.8)$. The odds ratio is the quotient of $\mathrm{LR}(\mathrm{X})$ and $\mathrm{LR}$ (non $\mathrm{X})$ and is a way of estimating the strength of association between an indicator and the survival ${ }^{18}$ the higher the odds, the greater the strength. For the analysis of functional outcome the same type of analysis was used. We compared two outcome groups, ie those with improved functional abilities and those (including patients who died during stay at the SCU) with a stable or deteriorating functional status.

\section{Results}

At the seven SCUs, 74 individuals (48 men and 26 women) were admitted in this period with neoplasms compressing the spinal cord. On 1-1-1991 16 patients were still alive. The cervical spine was the site of the epidural tumour in one case, the thoracic spine in 70 cases, and the lumbosacral spine in 3 cases. The spinal cord lesion was complete in 26 cases, the other 48 patients had an incomplete lesion.

\section{Survival}

Seven patients died during their stay at the SCU, 41 died within one year after discharge, while the other 26 patients lived longer than one year after discharge. Mean survival was 1483 days (range 45-6919 days) after the malignancy was diagnosed. The groups are shown in Table I.

A preliminary analysis revealed six indicators, which seemed to be related to prolonged survival after discharge (odds 
Table I Characteristics and mean data of total population and according to survival after discharge

\begin{tabular}{|c|c|c|c|}
\hline & \multirow{2}{*}{$\begin{array}{c}\begin{array}{c}\text { Total } \\
\text { population }\end{array} \\
n=74\end{array}$} & \multicolumn{2}{|c|}{ Survival after discharge: } \\
\hline & & $\begin{array}{c}<1 \text { year }^{\mathrm{a}} \\
n=48(65 \%)\end{array}$ & $\begin{aligned} & >1 \text { yearb }^{\mathrm{b}} \\
n & =26(35 \%)\end{aligned}$ \\
\hline Sex: $M$ & 48 & $34(71 \%)$ & $14(54 \%)$ \\
\hline $\mathrm{F}$ & 26 & $14(29 \%)$ & $12(46 \%)$ \\
\hline $\begin{array}{l}\text { Length of stay at the SCU } \\
\text { (days) }\end{array}$ & $111.7 \quad(6-432)$ & 98.7 & 135.8 \\
\hline $\begin{array}{l}\text { Survival after discharge } \\
\text { (days) }\end{array}$ & $423.7 \quad(0-1804)$ & 102.2 & 1017.3 \\
\hline \multicolumn{2}{|l|}{ Survival after SCI } & 267.5 & 1245.9 \\
\hline \multicolumn{4}{|l|}{ Tumour biology } \\
\hline Prostate & $15(20 \%)$ & $11(23 \%)$ & $4(15 \%)$ \\
\hline Breast & $14(19 \%)$ & $9(19 \%)$ & $5(19 \%)$ \\
\hline Lymphoma & $7(9 \%)$ & $4(8 \%)$ & $3(12 \%)$ \\
\hline Myeloma & $11(15 \%)$ & $2(4 \%)$ & $9(35 \%)$ \\
\hline Lung & $8(11 \%)$ & $8(17 \%)$ & 0 \\
\hline Kidney & $7(9 \%)$ & $3(6 \%)$ & $4(15 \%)$ \\
\hline Miscellaneous & $7(9 \%)$ & $6(13 \%)$ & $1(4 \%)$ \\
\hline Unknown & $5(7 \%)$ & $5(10 \%)$ & 0 \\
\hline \multicolumn{4}{|l|}{$\begin{array}{l}\text { General medical status } \\
\text { of the patient: }\end{array}$} \\
\hline Remission & $14(19 \%)$ & $11(23 \%)$ & $3(12 \%)$ \\
\hline Active & $35(47 \%)$ & $25(52 \%)$ & $10(38 \%)$ \\
\hline SCI pres sympt & $25(34 \%)$ & $12(25 \%)$ & $13(50 \%)$ \\
\hline \multicolumn{4}{|l|}{$\begin{array}{l}\text { Progression rate of } \\
\text { neurological symptoms: }\end{array}$} \\
\hline$<12 \mathrm{hrs}$ & $11(15 \%)$ & $6(13 \%)$ & $5(19 \%)$ \\
\hline $12-48 \mathrm{hrs}$ & $11(15 \%)$ & $11(23 \%)$ & 0 \\
\hline $2-7$ days & $25(34 \%)$ & $18(37 \%)$ & $7(27 \%)$ \\
\hline$>1$ week & $27(36 \%)$ & $13(27 \%)$ & $14(54 \%)$ \\
\hline \multicolumn{4}{|l|}{ Therapy used } \\
\hline Surgery & $8(11 \%)$ & $7(14 \%)$ & $1(4 \%)$ \\
\hline Radiotherapy & $42(57 \%)$ & $29(60 \%)$ & $13(50 \%)$ \\
\hline Combination & $21(28 \%)$ & $10(21 \%)$ & $11(42 \%)$ \\
\hline Other & $4(5 \%)$ & $3(6 \%)$ & $1(4 \%)$ \\
\hline \multicolumn{4}{|l|}{ Transfers at admission } \\
\hline Independent & $8(11 \%)$ & $5(10 \%)$ & $3(12 \%)$ \\
\hline Some assistance & $27(36 \%)$ & $14(29 \%)$ & $13(50 \%)$ \\
\hline Complete help & $39(53 \%)$ & $29(60 \%)$ & $10(38 \%)$ \\
\hline \multicolumn{4}{|c|}{ Bowel continence at admission } \\
\hline Normal & $34(46 \%)$ & $17(35 \%)$ & $17(65 \%)$ \\
\hline Less control & $25(34 \%)$ & $17(35 \%)$ & $8(31 \%)$ \\
\hline Complete loss & $15(20 \%)$ & $14(29 \%)$ & $1(4 \%)$ \\
\hline
\end{tabular}

${ }^{a}$ Including 7 patients who died during their stay at the SCU.

bIncluding the 16 patients who were still alive at 1-1-1991; all were discharged before 1-1-1990.

ratio $>2)$. These six indicators were scored 0 or 1 (see Table II). Tumour biology (lymphoma, myeloma, breast and kidney tumours), SCI as presenting symptom of the malignancy, slow ( $>1$ week) progression rate of neurological symptoms, tumour treated with a combination of surgery and radiotherapy, (partial) bowel control at 
Table II Indicators related to life expectancy: likelihood ratios, pre- and post-test probabilities of patients surviving longer than 1 year after discharge

\begin{tabular}{|c|c|c|c|c|c|}
\hline \multirow[b]{3}{*}{ Score $^{\mathrm{a}}$} & \multicolumn{5}{|c|}{ Survival $>1$ year after discharge } \\
\hline & \multicolumn{2}{|c|}{ Likelihood ratio } & \multirow{2}{*}{$\begin{array}{l}\text { Pre-test } \\
\text { probability }\end{array}$} & \multicolumn{2}{|c|}{ Post-test probability } \\
\hline & 0 & 1 & & 0 & 1 \\
\hline Tumour biology & 0.31 & $2.15^{\mathrm{b}}$ & $0.35^{\mathrm{c}}$ & 0.14 & 0.54 \\
\hline SCI presenting symptom & 0.67 & 2 & 0.35 & 0.27 & 0.52 \\
\hline $\begin{array}{l}\text { Progression rate } \\
\quad \text { neurological symptoms }\end{array}$ & 0.63 & 1.99 & 0.35 & 0.25 & 0.52 \\
\hline Therapy used & 0.72 & 2.03 & 0.35 & 0.28 & 0.52 \\
\hline $\begin{array}{l}\text { Transfer activities at } \\
\text { admission }\end{array}$ & 0.64 & 1.55 & 0.35 & 0.26 & 0.46 \\
\hline $\begin{array}{l}\text { Bowel continence at } \\
\text { admission }\end{array}$ & 0.13 & 1.36 & 0.35 & 0.07 & 0.39 \\
\hline
\end{tabular}

${ }^{a}$ Explanation of score

Tumour biology

0 : prostate, lung, miscellaneous and unknown tumours

1: breast, lymphoma, myeloma and kidney tumours.

General medical status

0 : tumour process active or in remission

1: SCI as the presenting symptom of the malignancy.

Progression rate of neurological symptoms

0 : shorter than one week

1: longer than one week.

Therapy used

0 : surgery or radiotherapy alone or other therapies

1 : combination of surgery followed by radiotherapy.

Transfer activities at admission

0 : complete help

1: with some assistance or independent.

Bowel continence at admission

0 : complete loss

1: less control or normal.

${ }^{b}$ A likelihood ratio for surviving longer than one year of 2.15 for tumour biology ' 1 ' $(\operatorname{LR}(1)=2.15)$ means that this type of tumour is found 2.15 times more often in patients who survive at least one year as compared to patients who die within one year.

'Pre-test probability: irrespective of test results, the probability of surviving at least one year after discharge is 26 out of 74 patients $=35 \%$. The information gain by the test result tumour biology ' 1 ' is reflected in the post-test probability of surviving more than one year $(54 \%)$ which has risen compared to the pre-test probability.

${ }^{\mathrm{d}}$ see Appendix I.

admission, and (partial) independence regarding transfer activities at admission were associated with survival more than one year.

No major differences (odds ratio $<2$ ) between the groups were found concerning: age (mean: 57 years, range 16-79); motor disorder at admission (MRC scale: $42 \%$ score $0-1 / 5,11 \%$ score $2 / 5,21 \%$ score $3 / 5$, $26 \%$ score $4-5 / 5)$; dressing, bathing and toileting at admission (38\% complete help, $53 \%$ some assistance, $9 \%$ independent); mobility at admission ( $5 \%$ house-walker, $81 \%$ wheelchair, $14 \%$ bedridden); and bladder continence $(28 \%$ normal, $5 \%$ less control, 3\% complete loss, $49 \%$ indwelling 
catheter, $15 \%$ intermittent catheterisation).

Table II gives not only the likelihood ratio for surviving more than one year, but also gives pre-test and the post-test probabilities for each of the six indicators.

Sum scores (range 0-6), consisting of the scores on the six mentioned indicators, were calculated for each patient. Table III lists these sum scores, the likelihood ratios and post-test probabilities. A patient with a sum score of $0-1$ has zero probability of living longer than one year after discharge, while a score of 5-6 yields a probability of 0.77 .

\section{Functional outcomes}

The functional level of 45 patients improved, while it did not change in 7 ; it deteriorated in 15 and the other 7 died. We looked again for the six indicators, in order to find predictors for a positive functional outcome of the rehabilitation programme. The scores are listed in Tables IV, $\mathrm{V}$ and VI. A patient with a sum score of $0-1$ has a 0.19 probability of functional improvement during stay at the SCU, a score of 5-6 yields a probability of 0.92 .

At admission 26 patients had a complete spinal cord lesion, with only 4 of them showing neurological improvement during their stay. At discharge 13 patients needed complete help with all activities of daily living (at admittance 23); 32 were completely independent (at admittance 4); 40 patients used an indwelling catheter or intermittent catheterisation; and bowel control in 40 patients was absent or reduced.
With regard to mobility at discharge, 23 patients were able to walk with or without aids, 37 used a wheelchair, while 7 were bedridden.

\section{Discharge disposition}

Regarding discharge disposition, 48 patients went home, 4 went to a nursing home, and the other 15 were transferred to a hospital because of complications. Of these last 15 patients, 8 went home, 2 went to a nursing home, and the other 5 died in the hospital.

\section{Discussion}

Rehabilitation services should be provided for those individuals who are able to benefit from them. How to select appropriate patients with neoplastic spinal cord compression for admittance to a SCU is still a matter of traditional clinical common sense because there are no known valid selection criteria. Besides survival and functional outcome the selection of these patients for inpatient rehabilitation services is based on the probability of returning home after discharge, which depends among other things on living accommodations (eg access for wheelchairs) and availability of home support. For survival and functional outcome, tumour biology, in line with the results in other studies, $2,4,6.7 .13 .15$ is the most important prognostic indicator. The likelihood ratio of each single prognostic factor is not high enough

Table III Numbers, likelihood ratios and post-test probabilities of sum scores of the six indicators related to survival after discharge

\begin{tabular}{|c|c|c|c|c|}
\hline \multirow[t]{2}{*}{ Sum score ${ }^{a}$} & \multicolumn{2}{|c|}{ Survival after discharge } & \multicolumn{2}{|c|}{ Survival $>1$ year after discharge } \\
\hline & $\begin{array}{l}>1 \text { year } \\
\text { No }\end{array}$ & $\begin{array}{l}<1 \text { year } \\
\text { hts }\end{array}$ & $\begin{array}{l}\text { Likelihood } \\
\text { ratio }^{b}\end{array}$ & $\begin{array}{l}\text { Post-test } \\
\text { Probability }\end{array}$ \\
\hline $0-1$ & 0 & 16 & 0 & 0 \\
\hline $2-4$ & 16 & 29 & 1.01 & 0.36 \\
\hline $5-6$ & 10 & 3 & 6.15 & 0.77 \\
\hline
\end{tabular}

aExlanation of sum score: see text.

bSee Appendix I. A likelihood ratio of 6.15 yields post-test odds of $3.32(6.15 \times 0.54)$. The probability that a patient with a sum score of 5-6 will live longer than 1 year after discharge is therefore 0.77 [3.32: $(1+3.32)]$. 
Table IV Functional level during stay at SCU

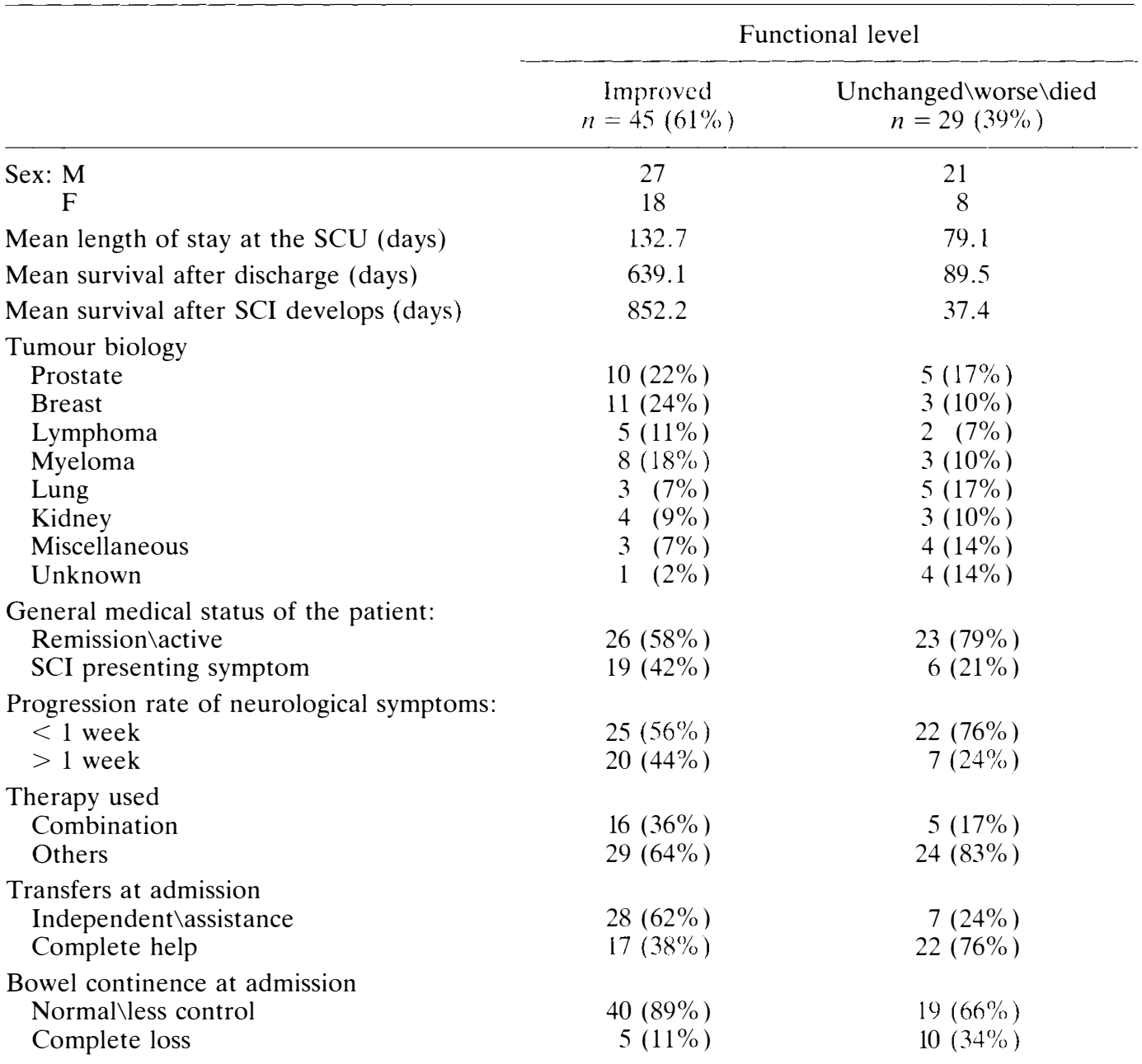

for it alone to justify a decision on admittance to a rehabilitation programme. The sum score as introduced in this study can be more helpful. It has a particularly high prognostic value when a patient's sum score is $0-1$. These patients have no chance $(0 \%)$ of living longer than one year after discharge. A sum score of 5 or 6 indicates a considerable chance $(77 \%)$ of the patient surviving for more than one year after discharge and therefore potentially benefiting from an intensive inpatient rehabilitation programme.

It seems that many rehabilitation candidates are not receiving necessary rehabilit- ation services. The proposed sum factor may improve selection of patients for rehabilitation services. Our method has to be validated by parallel studies, performed in general hospitals, to clarify the role of our sum score in classifying patients who would benefit most from an intensive inpatient rehabilitation programme.

At a SCU the rehabilitation programme is tuned to traumatic SCI. Although patients with a neoplastic SCI have the same impairments and disabilities, it should be clear to the patients (and the staff) that they need a completely different approach. It has been suggested that the rehabilitation of patients 
Table $\mathbf{V}$ Indicators related to functional outcome: likelihood ratios, pre- and post-test probabilities of patients with improved functional abilities

Functional improvement

\begin{tabular}{|c|c|c|c|c|c|}
\hline \multirow[b]{2}{*}{ Score: } & \multicolumn{2}{|c|}{ Likelihood ratio } & \multirow{2}{*}{$\begin{array}{l}\text { Pre-test } \\
\text { probability }\end{array}$} & \multicolumn{2}{|c|}{ Post-test probability } \\
\hline & 0 & 1 & & 0 & 1 \\
\hline Tumour biology & 0.46 & 3.61 & $0.61^{\mathrm{a}}$ & 0.42 & 0.85 \\
\hline $\begin{array}{l}\text { Progression rate neur } \\
\text { symptoms }\end{array}$ & 0.73 & 1.84 & 0.61 & 0.53 & 0.71 \\
\hline $\begin{array}{l}\text { SCI presenting } \\
\text { symptom }\end{array}$ & 0.73 & 2.04 & 0.61 & 0.53 & 0.76 \\
\hline Therapy used & 0.78 & 2.06 & 0.61 & 0.55 & 0.76 \\
\hline $\begin{array}{l}\text { Transfer activities } \\
\text { at admission }\end{array}$ & 0.50 & 2.58 & 0.61 & 0.44 & 0.80 \\
\hline $\begin{array}{l}\text { Bowel continence at } \\
\text { admission }\end{array}$ & 0.32 & 1.35 & 0.61 & 0.33 & 0.68 \\
\hline
\end{tabular}

a Pre-test probability $0.61(45: 74)$

Table VI Numbers, likelihood ratios and post-test probabilities of sum scores of the six factors related to functional outcome

\begin{tabular}{|c|c|c|c|c|}
\hline \multirow[t]{2}{*}{ Sum score } & \multicolumn{2}{|c|}{ Functional outcome } & \multicolumn{2}{|c|}{ Functional improvement at SCU } \\
\hline & Improved & $\begin{array}{l}\text { Unchanged } \backslash \text { worse } \backslash \text { died } \\
\text { No of patients }\end{array}$ & $\begin{array}{l}\text { Likelihood } \\
\text { ratio }\end{array}$ & $\begin{array}{l}\text { Post-test } \\
\text { probability }\end{array}$ \\
\hline$(0-1$ & 3 & 13 & 0.15 & 0.19 \\
\hline $2-4$ & 30 & 15 & 1.29 & 0.66 \\
\hline $5-6$ & 12 & 1 & 7.73 & 0.92 \\
\hline
\end{tabular}

with complete neoplastic injuries should be confined to instruction of the family, ${ }^{17}$ but our results show that important functional gains can be made. On the other hand the survival data in this study show that the rehabilitation programme has to be brief and to the point. Seven patients died during their stay at the SCU and 38 patients within one year of discharge. Their mean survival after discharge (102 days) was almost equal to their length of stay at the SCU (99 days). It is generally agreed that patients with a limited life expectation should spend as much time as possible with their relatives. Therefore we would emphasise early dis- charge home, as soon as basic rehabilitation goals have been reached.

\section{Appendix I}

Conversion of odds to probabilities:

$$
\text { probability }=\frac{\text { odds }}{1+\text { odds }}
$$

Calculation of post-test odds:

pre-test odds $\times$ likelihood ratio $=$

post-test odds

Odds ratio: $\frac{\operatorname{LR}(1)}{\operatorname{LR}(0)}$

\section{References}

I Barron KD, Hirano A, Araki S. Terry RD (1959) Experiences with metastatic neoplasms involving the spinal cord. Neurology 9: 91-106. 
2 Byrne ThN, Waxman SG (1990) Neoplastic causes of spinal cord compression: epidural tumors. In: ThN Byrne, SG Waxman, editors. Spinal Cord Compression: Diagnosis and Principles of Management. FA Davis Company, Philadelphia: 146-176.

3 Ampil FL (1989) Epidural compression from metastatic tumor with resultant paralysis. J Neuro-onco 7: 129-136.

4 Dunn RC, Kelly WA, Wohns RNW, Howe JF (1980) Spinal epidural neoplasia: A 15-year review of the results of surgical therapy. J Neurosurg 52: 47-51.

5 Livingston KE, Perrin RG (1978) The neurosurgical management of spinal metastases causing cord and cauda equina compression. J Neurosurg 49: 839-843.

6 Soelberg Sorenson P, Borgesen SE, Rohde K, Rasmussen B, Bach F, Bøgen-Rasmussen T et al (1990) Metastatic epidural spinal cord compression: results of treatment and survival. Cancer 65: 1502-1508.

7 Stark RJ, Henson RA, Evans SJW (1982) Spinal metastases: A retrospective survey from a general hospital. Brain 105: 189-213.

8 Young RF, Post EM, King GA (1980) Treatment of spinal epidural metastases. Randomized prospective comparison of laminectomy and radiotherapy. J Neurosurg 53: 741-748.

9 Constans JP, Diviitis E de, Donzelli ER, Spaziante R, Meder JF, Haye C (1983) Spinal metastases with neurological manifestations: Review of 600 cases. J Neurosurg 59: 111-118.

10 Sundaresan N, Galicich JH, Lane JM, Bains MS, McCormack P (1985) Treatment of neoplastic epidural cord compression by vertebral body resection and stabilization. J Neurosurg 63: 676-684.

11 Woerkom-Eijkenboom WMH van, Braakman R (1981) Paraplegia due to spinal epidural neoplasia. Paraplegia 19: 100-106.

12 Acigoz B, Akkurt C, Erbengi A, Bertan V, Ozgen T, Ozcan O (1989) Metastatic spinal cord tumours. Paraplegia 27: 359-363.

13 Barcena A, Lobato RD, Rivas JJ, Cordobes F, Castro de S, Cabrera A et al (1984) Spinal metastatic disease: Analysis of factors determining functional prognosis and the choice of treatment. Neurosurgery 15: $820-827$.

14 Helweg-Larsen S, Rasmusson B, Soelberg Sorenson P (1990) Recovery of gait after radiotherapy in paralytic patients with metastatic epidural spinal cord compression. Neurology 40: 1234-1236.

15 Onimus M, Schraub S, Bertin D, Bosset JF, Guidet M (1986) Surgical treatment of vertebral metastasis. Spine 11: 883-891.

16 Siegal T, Siegal T (1985) Surgical decompression of anterior and posterior malignant epidural tumors compressing the spinal cord: a prospective study. Neurosurgery 17: 424-432.

17 Murray P (1985) Functional outcome and survival in spinal cord injury secondary to neoplasia. Cancer 55: 197-201.

18 Sackett DL, Haynes RB, Tugwell P (1991) Clinical Epidemiology. A Basic Science for Clinical Medicine. Little, Brown and Company, Boston/Toronto. 